\title{
Study of the Characterization of Partial Purified Polyamine Oxidase from Sheep's Brain Tissue
}

\author{
Wathba Idrees Ali \\ Sarah Abdulelah Younis \\ Chemistry department / College of Education For pure science \\ University of Mosul \\ Wathba.ali@gmail.com \\ sarah.younis@gmail.com \\ DOI: $\underline{10.33899 / \text { edusj.2019.162978 }}$ \\ Received \\ Accepted \\ 24 / 12 / 2018 \\ 29 / 01 / 2019
}

\begin{abstract}
The study included partially purified of polyamine oxidase (PAO) from sheep's brain tissue by dialysis and ion exchange chromatography using DEAEcellulose techniques. Tow isoenzymes (I/II) were obtained with specific activities 3.876 and 2.856 units/ $\mathrm{mg}$ of protein and purification folds 11,8 times respectively compared with crude enzyme.

The specific activity of PAO I was better than PAO II, thus we considered it for following studying. The optimal condition showed $100 \mu \mathrm{L}$ volume of enzyme, $\mathrm{pH}=9,40^{\circ} \mathrm{C}$, at incubation time $10 \mathrm{~min}$. Some of properties of partially purified PAO enzyme were studied and the specificity was found to be superior to the base material, where it was given the highest activity when using spermidine. Using lineweaver_Burk plot, the values of maximum velocity $\left(\mathrm{V}_{\max }\right)$ and Michaelis constant $\left(\mathrm{K}_{\mathrm{m}}\right)$ were found to be $0.145 \mathrm{Unit} / \mathrm{ml}$ and $43.4 \mathrm{mM}$ respectively, and potassium ion was the most activator ion to the enzyme arrived to $233.8 \%$. The compounds (ammonium chloride, sodium fluoride, phenyl hydrazine, sodium azide and EDTA) showed a significant inhibitory effect on the activity of the enzyme $(56.1 \%, 49.9 \%$, $49.9 \%, 37.3 \%$ and $25 \%$ ) respectively.
\end{abstract}

Key words: Polyamine, Polyamine oxidase, Sheep's brain tissue 
دراسة خصائص أنزيم بولي أمين أوكسيديز المنقى جزئياً من نسيج دماغ الأغنام

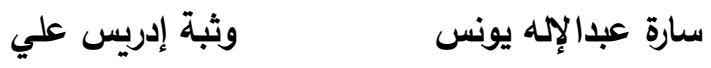 \\ قسم الكيمياء / كلية التربية للعلوم الصرفة

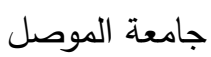

Wathba.ali@gmail.com

sarah.younis@gmail.com

DOI: $\underline{10.33899 / \text { edusi.2019.162978 }}$

القبول

الاستلام

2019 / 01 / 29

2018 / 12 / 24

\title{
الخلاصة
}

تضــنت الدراسـة تتقيـة جزئيـة لأنـزيم بـولي أمسين أوكسـيديز مـن نسـيج دمـاغ الأغنـام, باسـتعمال

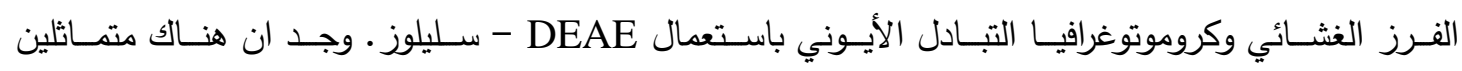

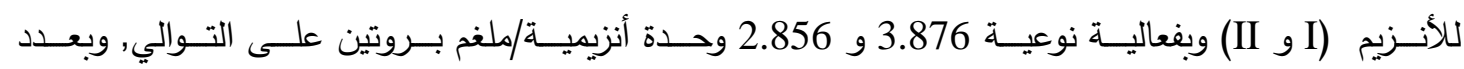
مرات تتقية 11 و 8 مرة على التوالي مقارنة بالأنزيم الخام.

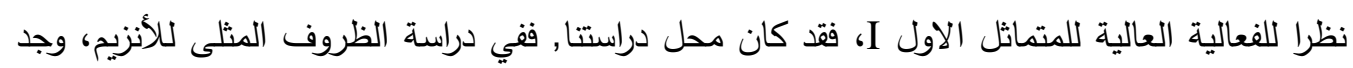

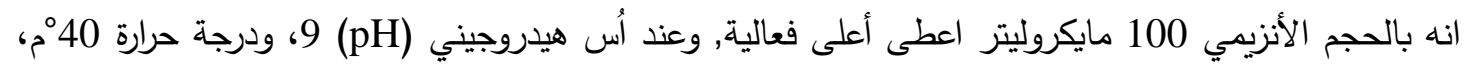

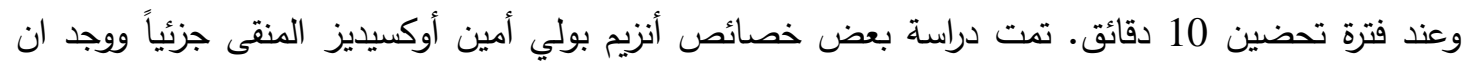

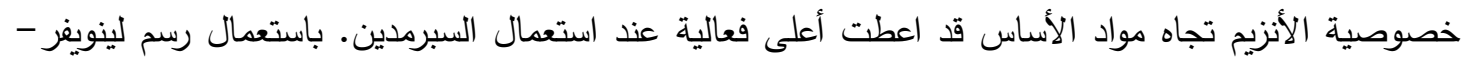

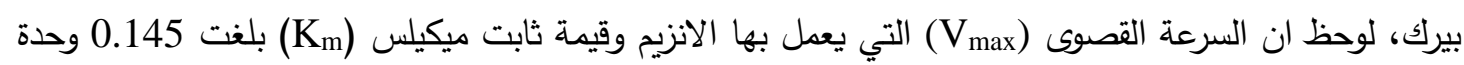

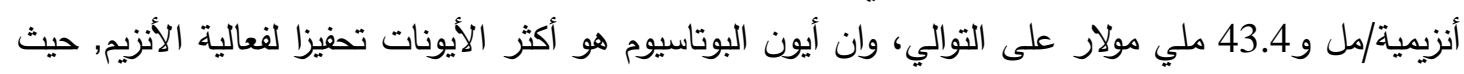

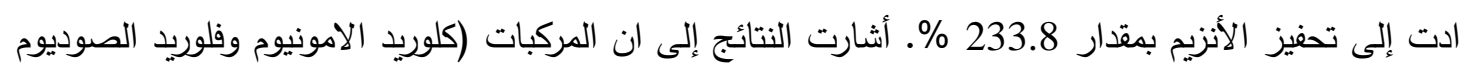

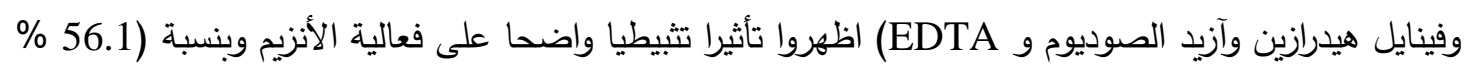

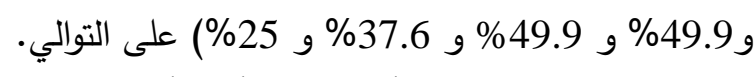
الكلمات المفتاحية:- بولي أمين, بولي أمين أوكسيديز , نسيج دماغ الأغنام.

المقدمة

مركبات متعدد الأمين Polyamines (PA) هي مركبات عضوية حيوية ذات وزن جزيئي واطئ تتكون

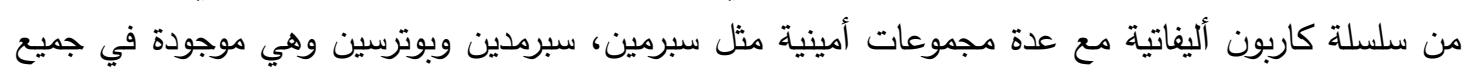
أنواع خلايا الثدييات والنباتات[1]. وتعد هذه المركبات مكونات طبيعية لجميع الخلايا الحية بدائية النواة وحقيقية

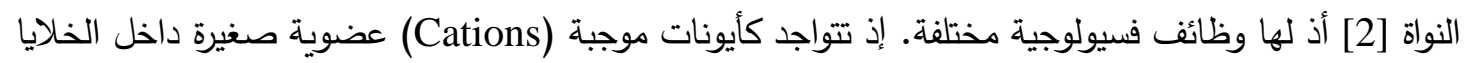

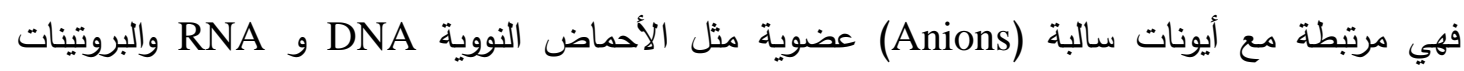

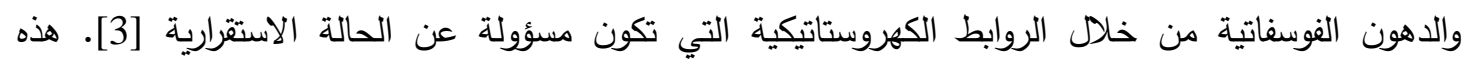

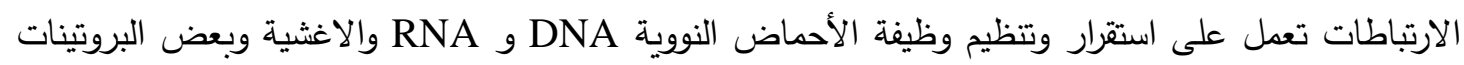

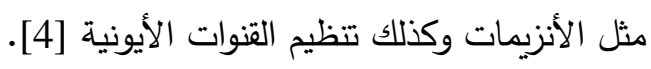


أنزيمات بولي أمين أوكسيديز Polyamine Oxidase PAOs هي أنزيمات ذات أهمية في العمليات الحيوية، هي عبارة عن وحدات يتراوح وزنها الجزيئي من (50-60) كيلودالتون [5]. توجد هذه الأنزيمات في في التئي

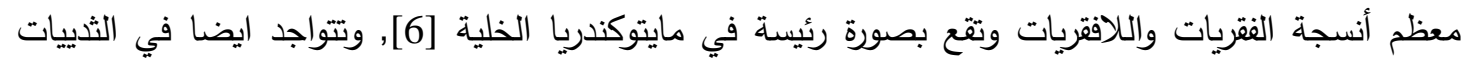
والنباتات والبكتريا والفطريات [7]. تمت دراسة هذه الأنزيمات في أنسجة وأعضاء مختلفة منها كبد الجرذي واتي

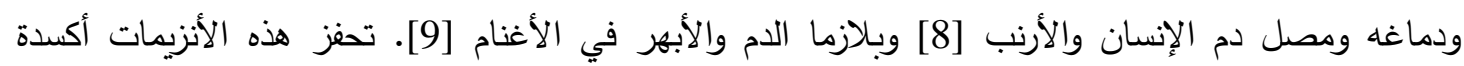
مجموعة الأمين الطرفية، الحرة أو المستبدلة, ويكون ناتج التفاعل الديهايد وبيروكسيد الهيدروجين وأيون الأمونيوم

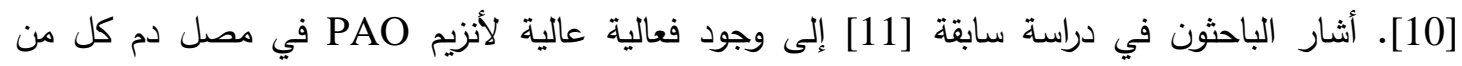

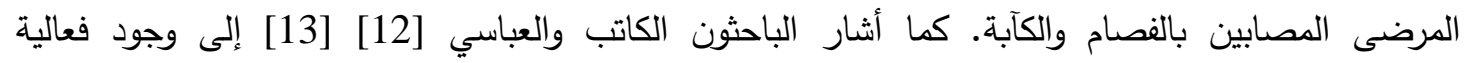
لأنزيم PAO في سائل النخاع الثوكي للأطفال السليمين والمصابين بالتهاب السحايا الفيروسية أو الجرثومية.

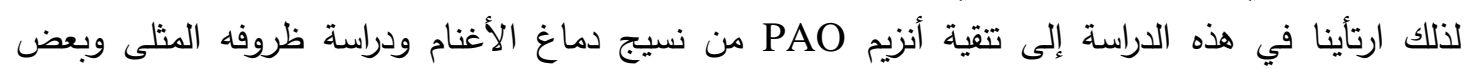

\section{المواد وطرائق العمل}

تنقية و دراسة خواص أنزيم PAO من نسيج دماغ الأغنام:

1- تحضير المستخلص الخام

أخذ 100 غم من نسيج دماغ الأغنام (ذكر سليم)، وسحقت باستعمال ألة السحق Blender لمدة 10 ملفير

دقائق ومزجت مع محلول الفوسفات المنظم

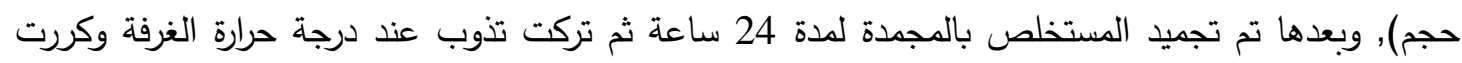

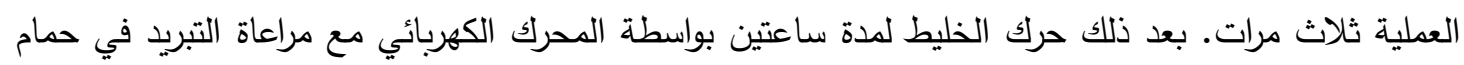

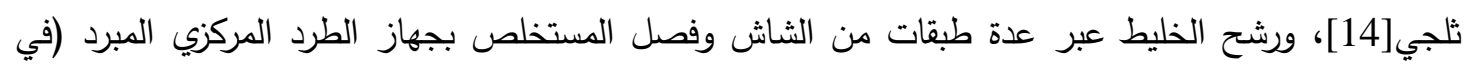
كلية التربية للعلوم الصرفة/ مختبرات علوم الحياة) للتخلص من المواد غير الذائبة لمدة 10 دقائق بسرعة (3000xg) للحصول على راشح رائق, وقيس حجم الراشح الذي يمثل حجم المستخلص الخام, ثم قدر تركيز

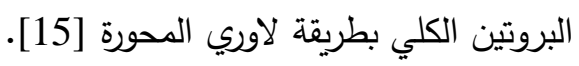

قياس فعالية الأنزيم

تم قياس فعالية أنزيم PAO باستعمال طريقة الباحث Flayeh المحورة [16] وتتضمن الطريقة أكسدة

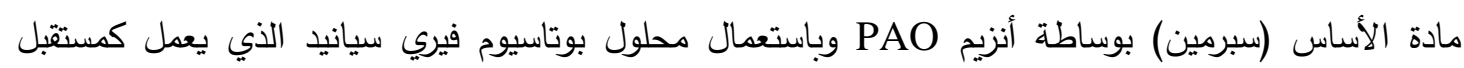

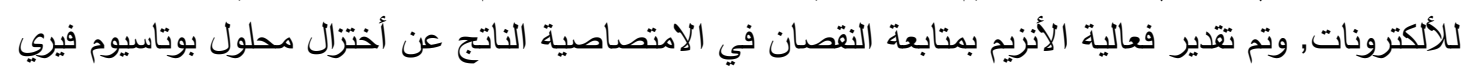

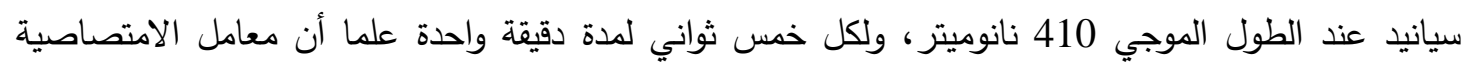

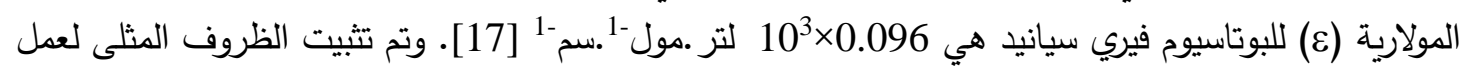
أنزيم PAO في نسيج دماغ الأغنام في جميع التجارب الناحقة.

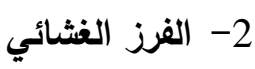

تمت عملية الفرز الغشائي للمستخلص الخام الناتج من الخطوة السابقة وبحجم (12) مل لمدة 20 ساعة, وفي درجة حرارة 4م باستعمال محلول الفوسفات المنظم نوع

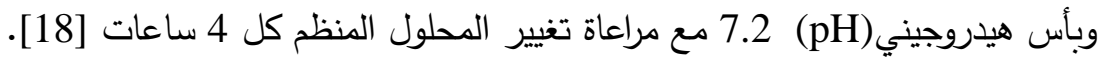


3- كروموتوغرافيا التبادل الأيوني

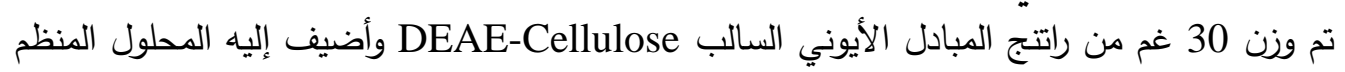

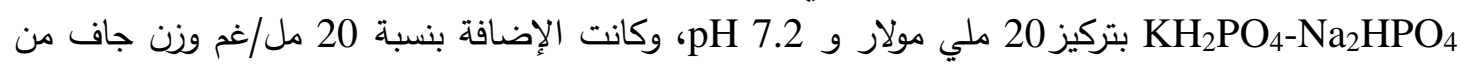

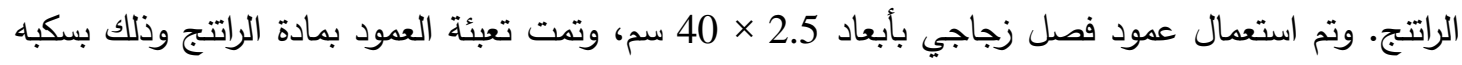

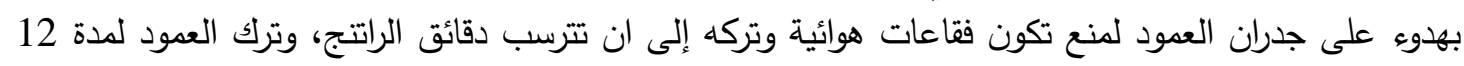

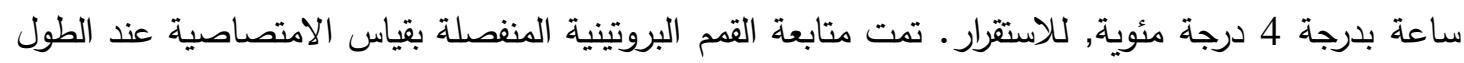

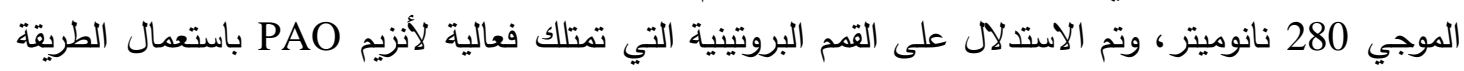

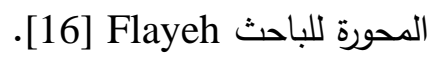

\section{النتائج والمناقشة : \\ تنقية أنزيم PAO من نسيج دماغ الأغنام :}

أشارت نتائج التتقية الجزئية لأنزيم PAO من نسيج د نسيج دماغ الأغنام والمبينة في الجدول (1) إلى وجود

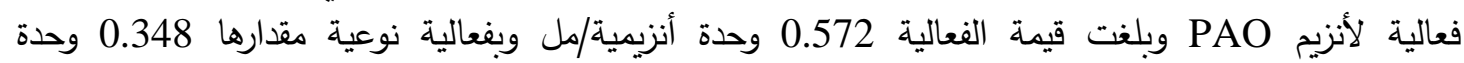

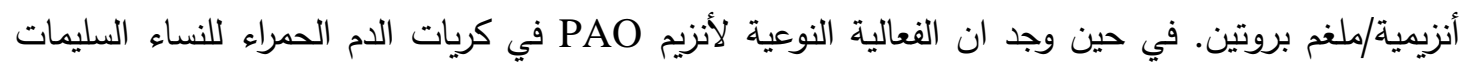
بلغت 0.0184 وحدة أنزيمية/ملغم بروتين [19]. كما لوحظ وجود فعالية للأنزيم في كبد الإنسان واني وان فعان فعاليته كانت أعلى مما في البنكرياس [20] ـ كما بينت النتائج ان الفعالية النوعية لأنزيم

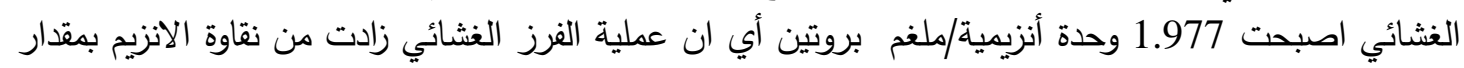

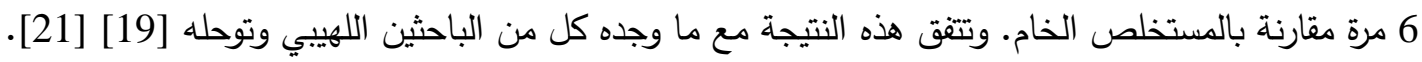

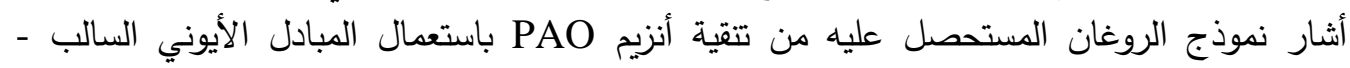
سليلوز إلى وجود قمتين متميزتين تمتلكان فعالية لأنزيم PAEAE عند حجم روغان (Peak I)

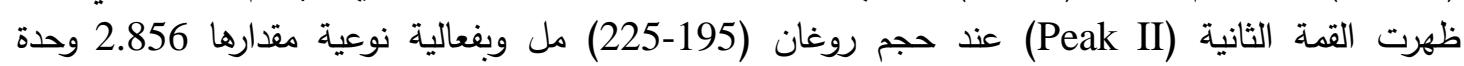
أنزيمية/ملغم بروتين مما يدل على ان أنزيم PAO المنقى يحمل محصلة شحنة سالبة معاكسة لثحنة المبادل

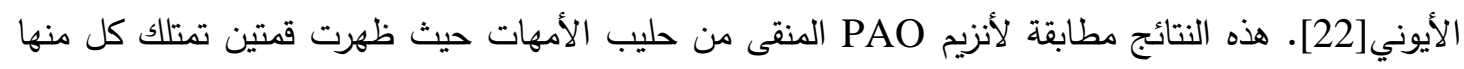

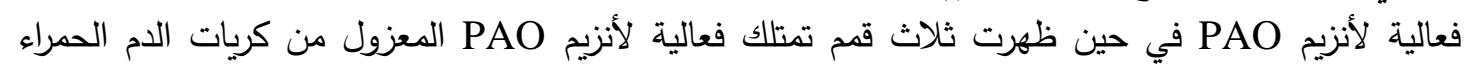

جدول رقم (1): خطوات تنقية أنزيم PAO من نسيج دماغ الأغنام.

\begin{tabular}{|c|c|c|c|c|c|c|c|}
\hline $\begin{array}{c}\text { الفعالية } \\
\text { استرجاع }\end{array}$ & مرات & (الفعالية النوعية & 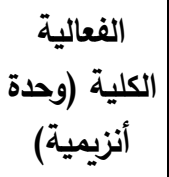 & |أنزيمية & $\begin{array}{c}\text { الكركيز } \\
\text { البروتين (ملفم) }\end{array}$ & (الكلي & خطوات التنقية \\
\hline 100 & 1 & 0.348 & 51.48 & 0.572 & 148.05 & 90 & المستخلص الخام \\
\hline 65.57 & 6 & 1.977 & 33.756 & 2.813 & 17.076 & 12 & الفرز الفشائي \\
\hline & & & & & & & التبادل الأيوني \\
\hline 31.89 & 11 & 3.876 & 16.415 & 0.469 & 4.235 & 35 & القمة I I \\
\hline 24.30 & 8 & 2.856 & 12.51 & 0.417 & 4.38 & 30 & II القمة \\
\hline
\end{tabular}

* الوحدة الأنزيمية تشير إلى كمية الأنزيم اللازمة لأكسدة مايكرومول واحد من المادة الأساس (السبرمين) في الدقيقة الواحدة تحت

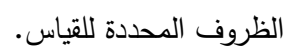




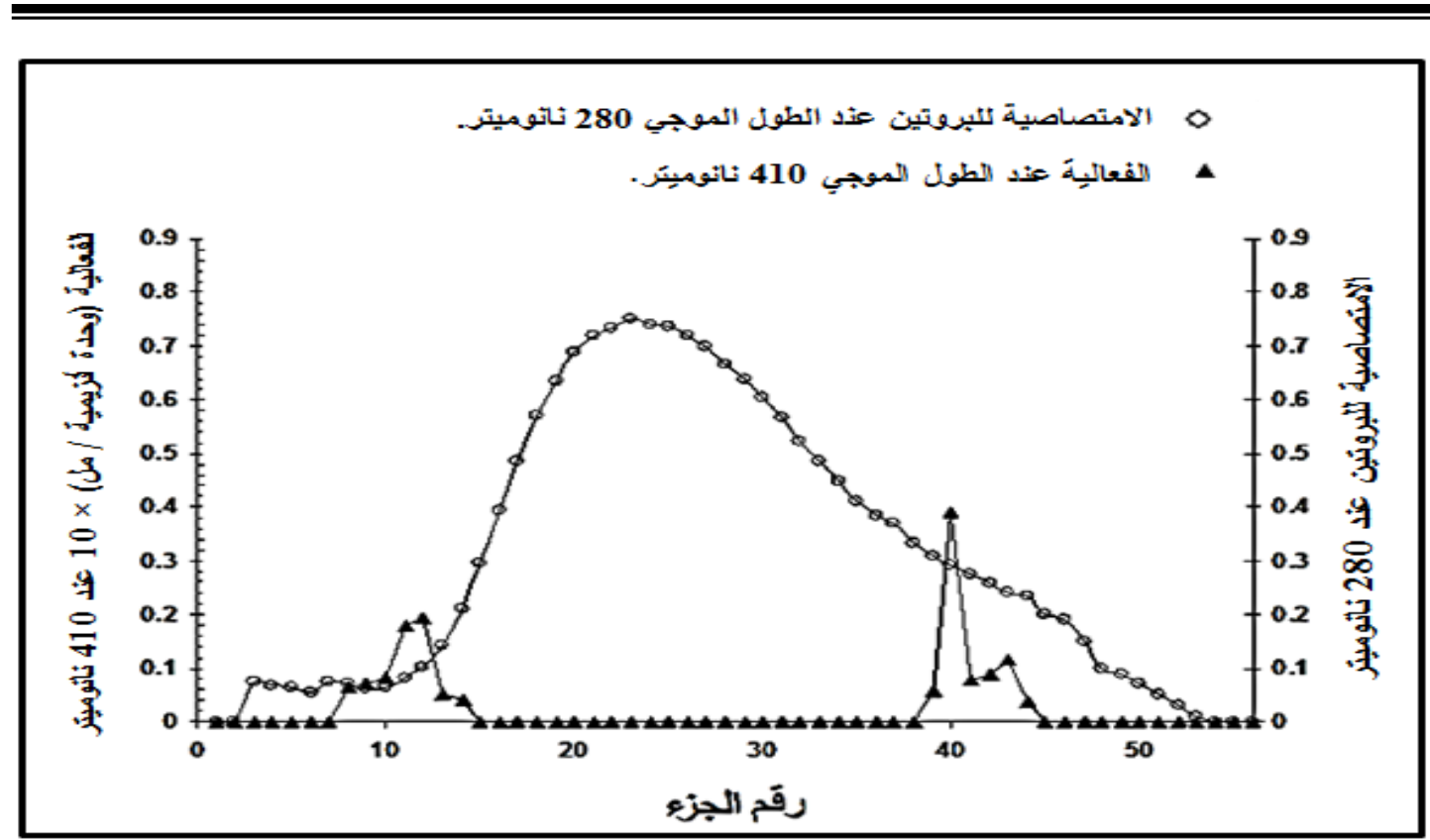

الثكل (1): نموذج الروغان المستحصل من تنقية أنزيم PAO من نسيج دماغ الأغنام بتقنية كروموتوغرافيا التبادل الأيوني (حجم 5 (حم)

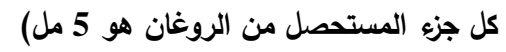

دراسة الظروف المثلى للقمة I التابعة لأنزيم PAO المنقى من نسيج دماغ الأغنام

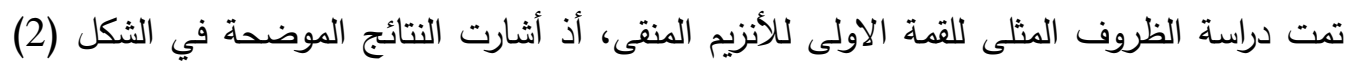

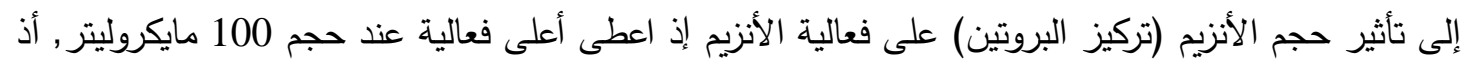

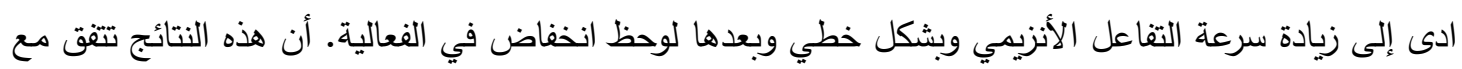

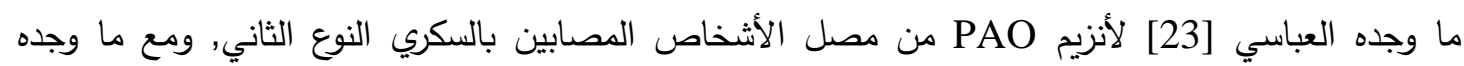

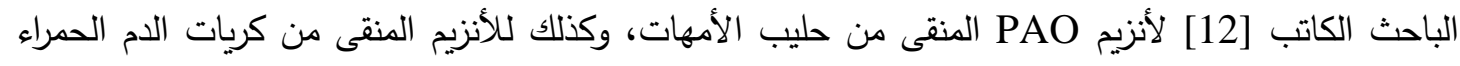

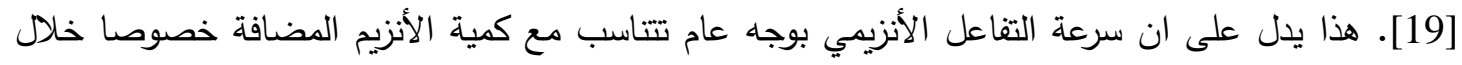

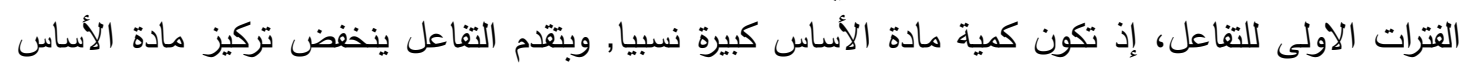

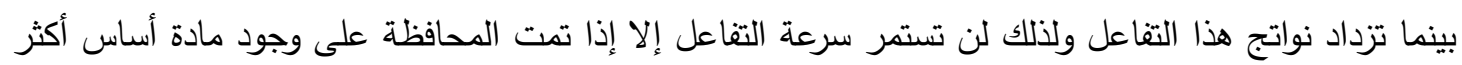
من تركيز الأنزيم، ويمكن القول أن سرعة التفاعل الأنزيمي تتناسب طرديا مدع تركيز الأنزيم [24].

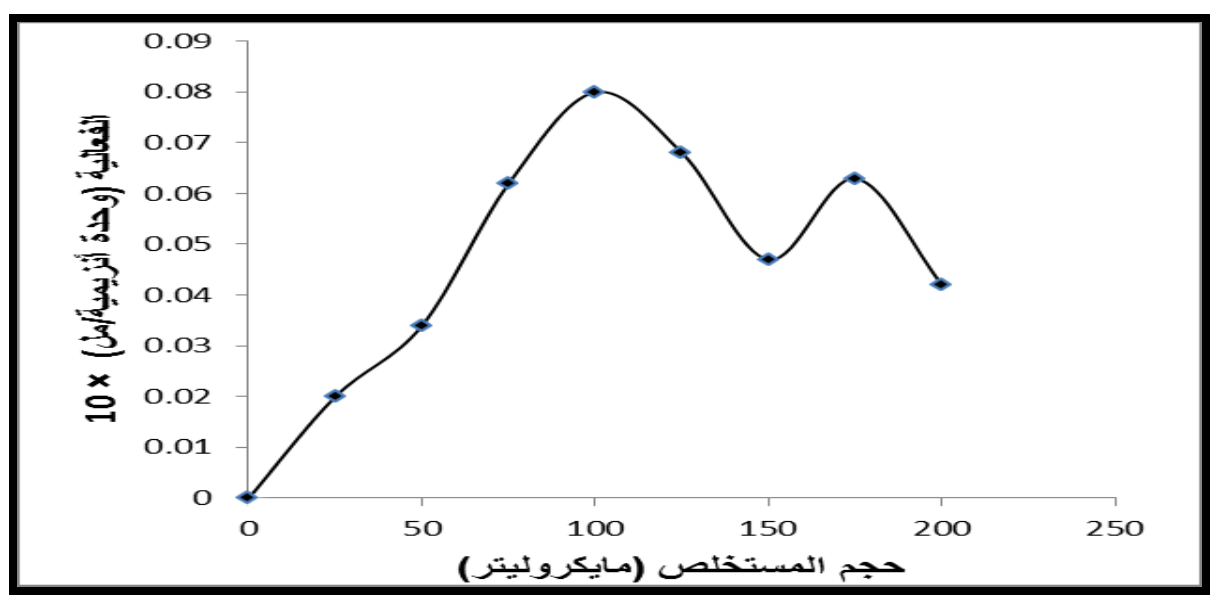

شكل (2): تأثير حجم الأنزيم على سرعة التفاعل الانزيمي 
وأثارت النتائج ألموضحة في الثكل (3) ان الفعالية الأنزيمية بلغت سرعتها القصوى عند زمن حضن

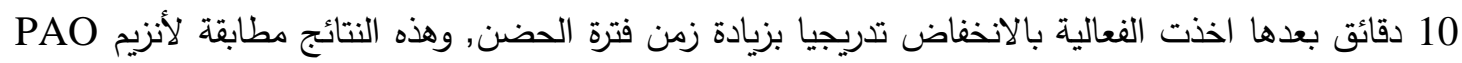

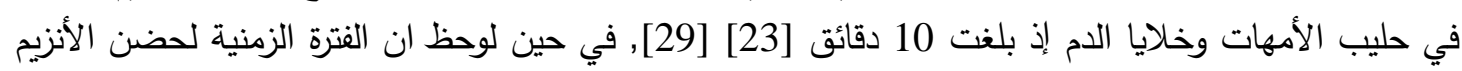

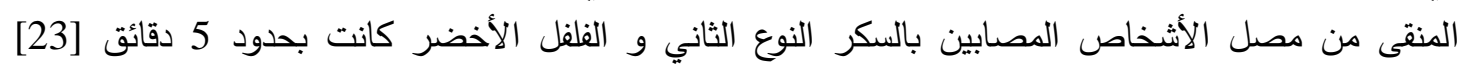

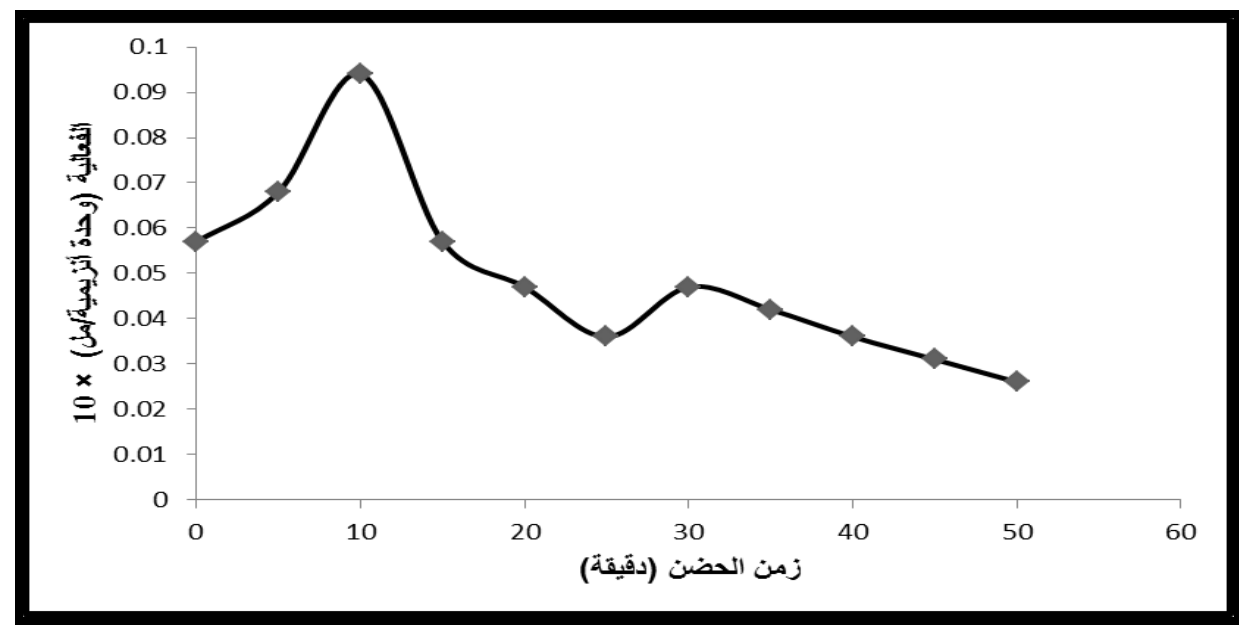

شكل (3): تأثير زمن الحضن على سرعة التفاعل الأنزيمي

أشارت النتائج المبينة في الثكل (4) إلى ارتفاع تدريجي في قيم فعالية الأنزيم بارتفاع درجة الحرارة إذ إذار

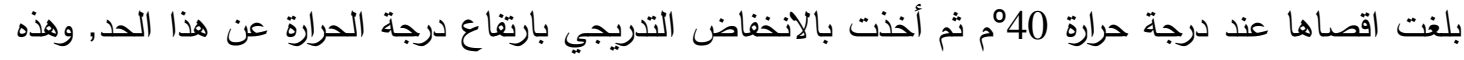

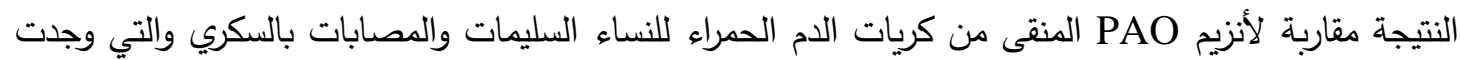

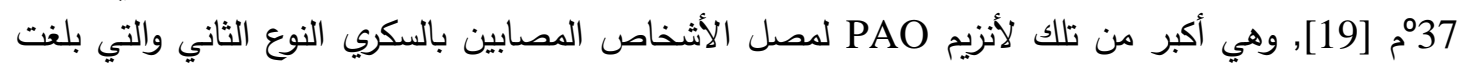

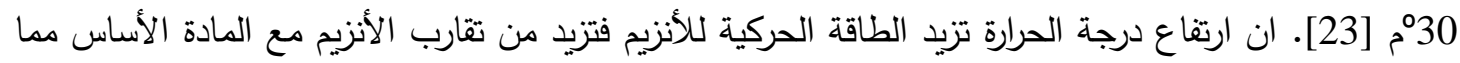

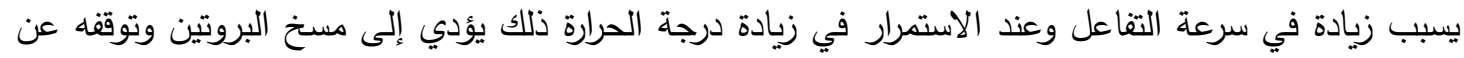

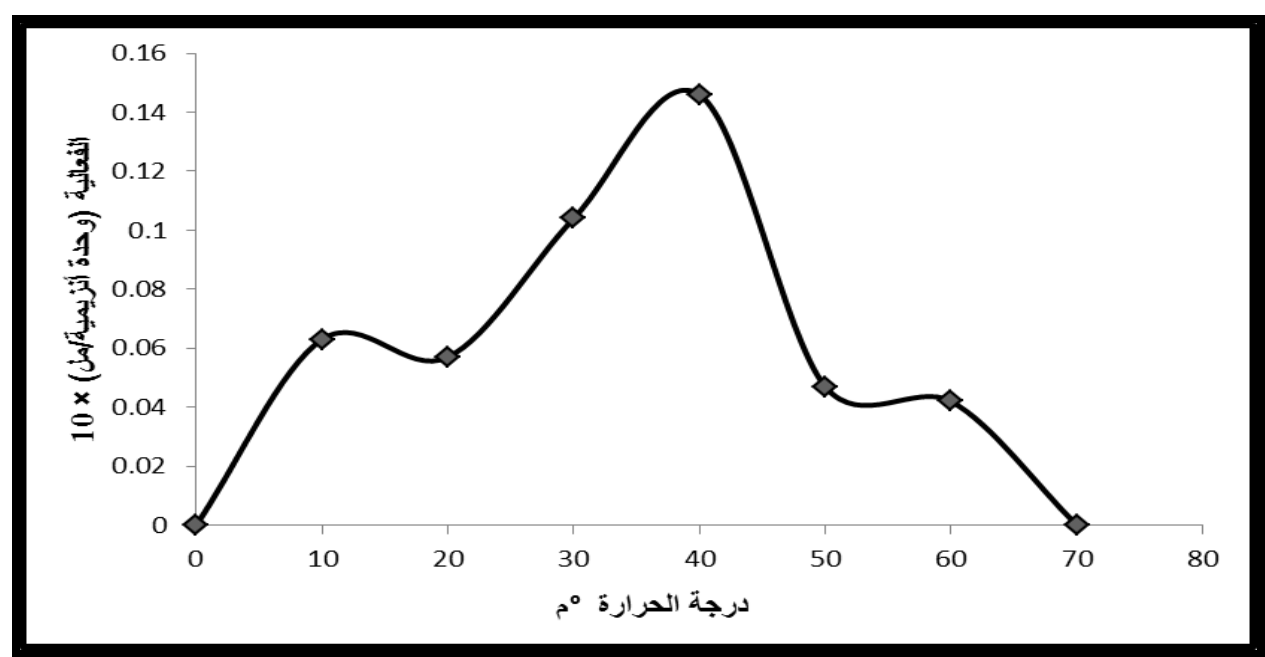

شكل (4): تأثير درجة الحرارة على سرعة التفاعل الأنزيمي 
وأشارت النتائج إلى ان أعلى فعالية للأنزيم وجدت عند الأس الهيدروجيني (9) كما في الثكل (5) وباستخدام محلول الفوسفات المنظم

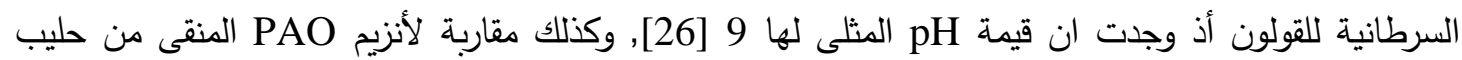

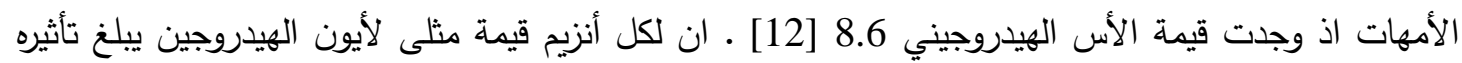

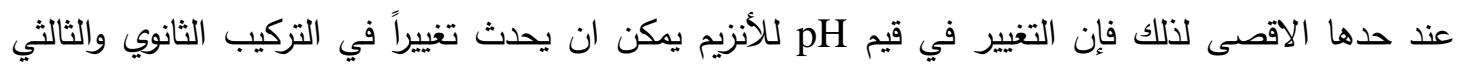
لجزيئة الأنزيم أو للموقع الفعال مما يؤثر على سرعة التفاعل الأنزيمي.

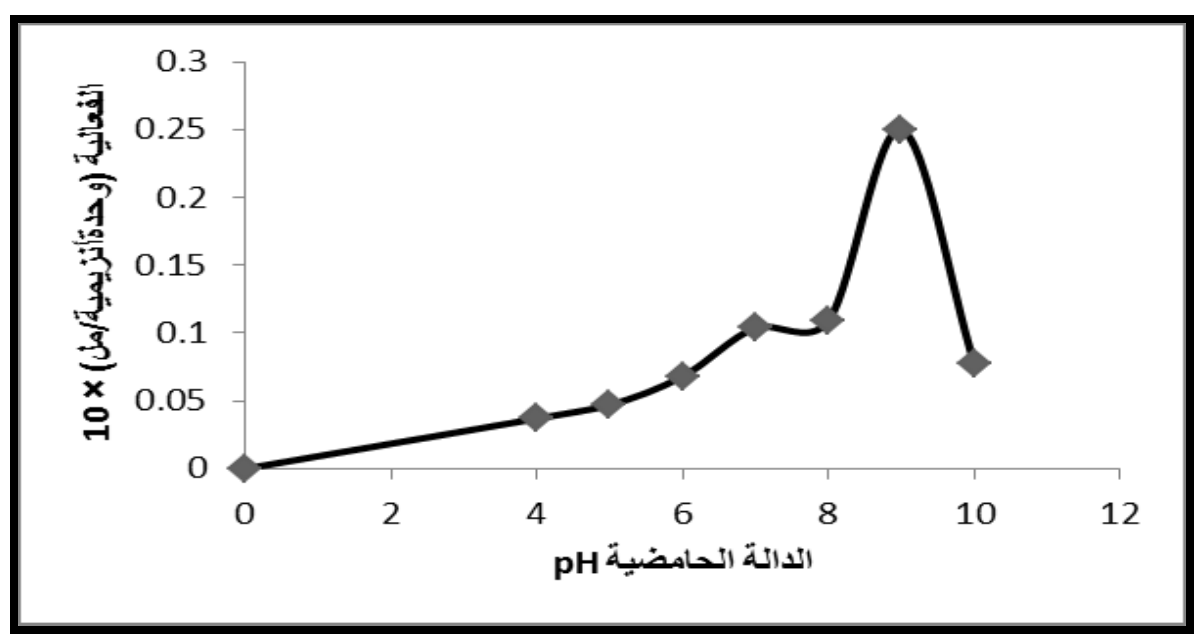

شكل(5): تأثير الدالة الحامضية على سرعة التفاعل الأنزيمي

بينت النتائج كما موضح بالثكل (6), ومن خلال معادلة لينويفير - بيرك Linewaver - Burk ان

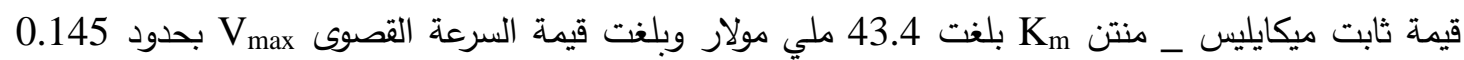
وحدة أنزيمية/مل باستعمال السبرمين كمادة أساس، ان قيمة KAO هذه تتفق مع قيم لمتماثلات أنزيم

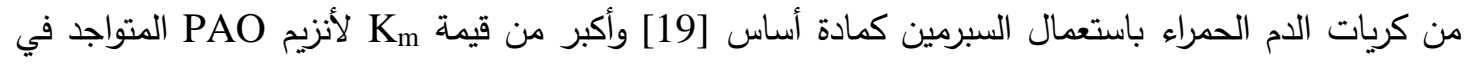

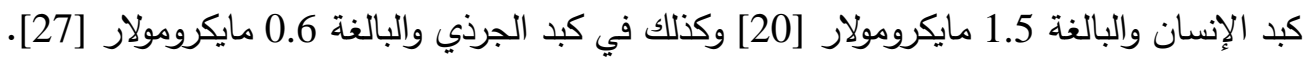

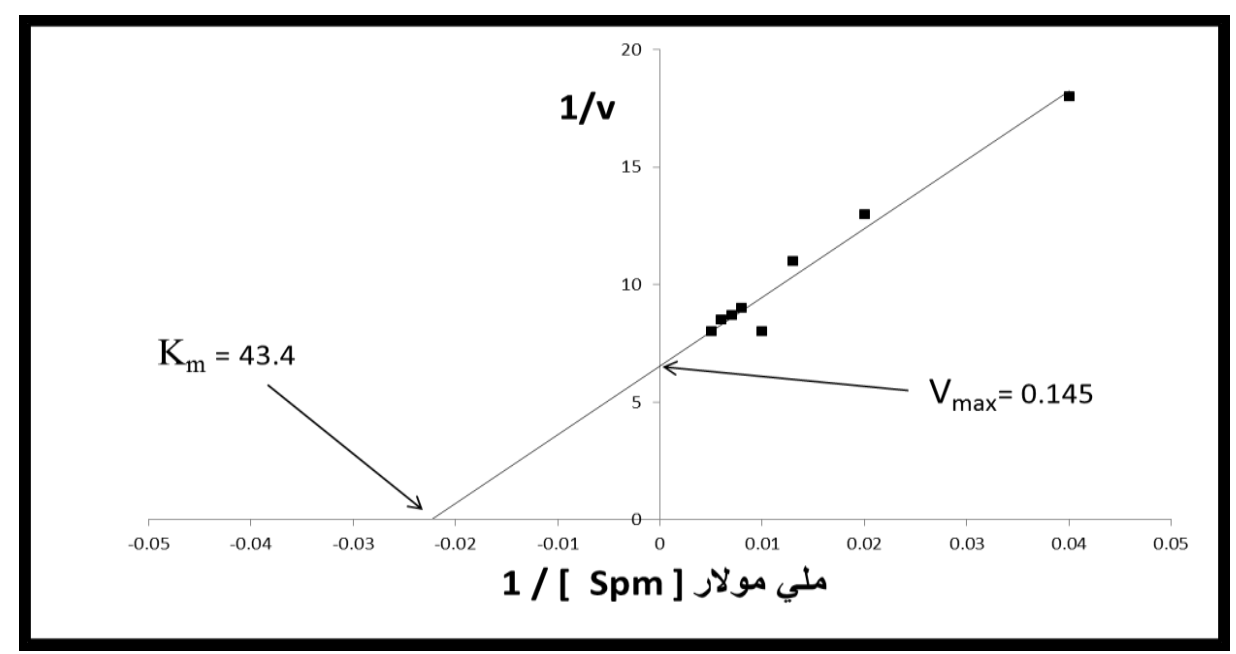

شكل (6): رسم لينويفر - بيرك لأنزيم PAO المنقى من نسيج دماغ الأغنام. 
خصائص أنزيم PAO I المنقى:

أشارت النتائج في الجدول (2) إلى خصوصية أنزيم PAO I المنقى جزئيا من نسيج دماغ الأغنام تجاه

مواد أساس مختلفة, ولوحظ ان أعلى فعالية لأنزيم PAO ظهرت باستعمال المادة الأساس السبرمدين تليها

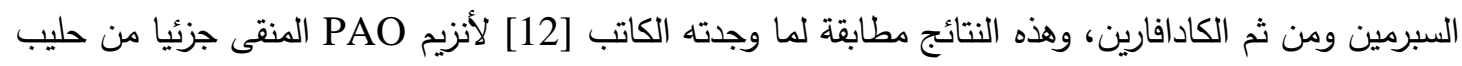

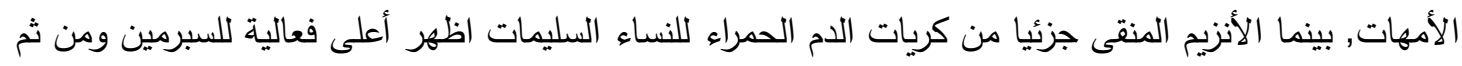

السبرمدين [19].

جدول (2): خصوصية أنزيم PAO I المنقى من نسيج دماغ الأغنام تجاه مواد أساس مختلفة

\begin{tabular}{|c|c|}
\hline الفعالية النسبية (\%) & مادة أساس (100 ملي مولار) \\
\hline 100 & سبرمين \\
\hline 187.6 & سبرمدين \\
\hline 82.0 & كادافارين \\
\hline 76.4 & هكسايل أمين \\
\hline 58.4 & بيوتايل أمين \\
\hline 47.2 & ثنائي أمين بروبان \\
\hline 40.44 & بنزايل أمين \\
\hline
\end{tabular}

وأثارت النتائج المبينة في الجدول (3) إلى تأثير التنشيطي لبعض الأيونات على فعالية أنزيم PAO

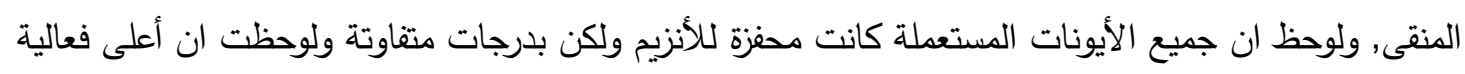
للأنزيم كانت عند استعمال أيون البوتاسيوم K حيث اصبحت الفعالية الأنزيمية أكثر مقارنة بنموذج السيطرة الخالي من إضافة الأملاح, وهذه النتيجة مطابقة لما وجده اللهيبي [19] لأنزيم PAO في كريات الدم الحمراء للنساء إذ كانت أفضل فعالية للأنزيم عند استعمال أيون Kن وبتركيز 10 ملي مولار , وكذلك مطابقة لأنزيم PAO من مصل الأشخاص المصابين بالسكر غير المعتمد على الأنسولين [23], بينما لوحظ ان أعلى فعالية لأنزيم PAO في حليب الأمهات كانت بوجود أيون الكالسيوم Ca التأثير الملاحظ لهذه الأيونات على الفعالية الأنزيمية إلى الدور الذي تحدثه في الحفاظ على البيئة الفراغية الملائمة لإحداث التأثير التحفيزي للأنزيم, ويمكن تفسير الزيادة في الفعالية في ان الأيون المضاف يعلى يعل على فلى

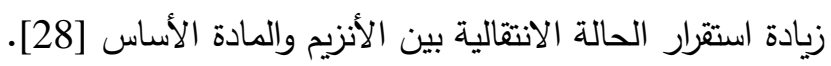


جدول(3): التأثير التنثيطي لبعض الأيونات المختلفة على فعالية أنزيم PAO I المنقى من نسيج دماغ الأغنام

\begin{tabular}{|c|c|}
\hline الفعالية النسبية \% & ملح الأيون المضاف (10 ملي مولار) \\
\hline 100 & محلول السيطرة \\
\hline 233.8 & كلوريد البوتاسيوم \\
\hline 209.4 & كلوريد الكالسيوم \\
\hline 178 & كلوريد الصوديوم \\
\hline 166.9 & كلوريد المغنيسيوم \\
\hline 133.5 & كبريتات الألمنيوم \\
\hline
\end{tabular}

أشارت النتائج الموضحة في الجدول (4) إلى التأثير التثبيطي لبعض المركبات على فعالية أنزيم PAO المنقى، إلى أن حضن المركب كلوريد الأمونيوم NH4Cl مع الأنزيم ادى إلى تثبيط واضح لفعالية أنزيم

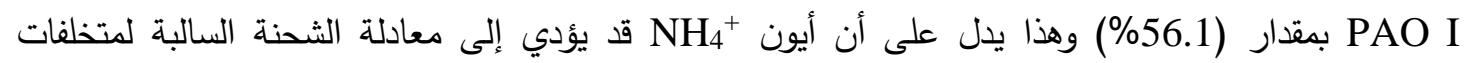
الأحماض الأمينية والتي قد تؤدي دورا مهما في فعالية أنزيم PAO [29]. بينما أظهرت المركبات فلوريد الصوديوم وآزيد الصوديوم وفينايل هيدرازين تأثيرات مختلفة, والتي عرفت بأنها تكون معقدات مع الأيونات

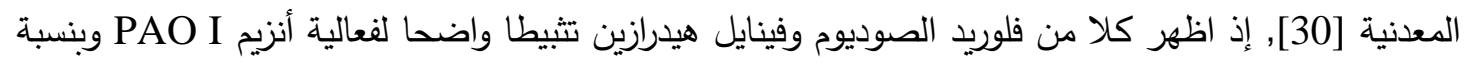
(49.9\%) لكل منهما, مما يدل على مشاركة مجاميع الكاربونيل للفنينايل هيدرازين في فعالية الأنزيم [31], بينما ادى المركب هيدروكسي للفينايل هيدرازين إلى تثبيط بنسبة (50\%) من فعالية أنزيم PAO المتواجد في الثعير [32]. بينما وجدت الكاتب [12] تأثيراً تثبيطياً واضحاً لأنزيم PAO في هليب الثيب الأمهات لكل من فلوريد

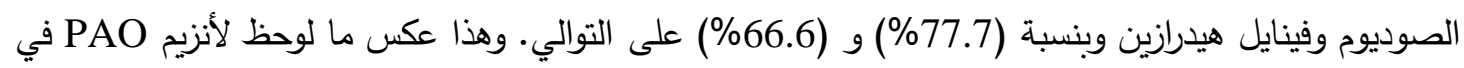

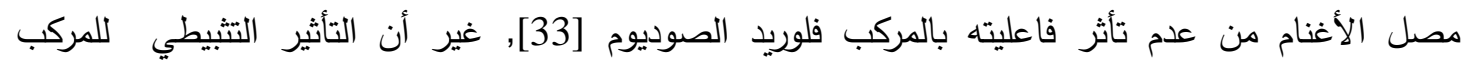
EDTA

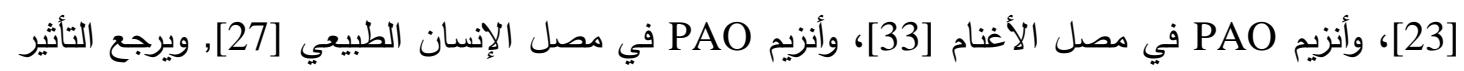

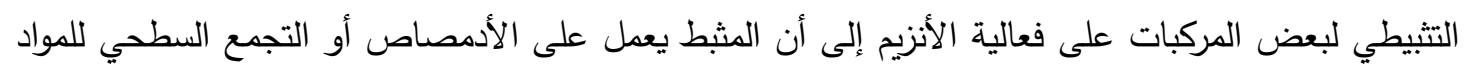

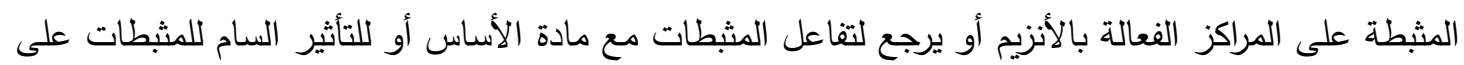
بروتينات الأنزيم [24]. 


\begin{tabular}{|c|c|}
\hline منقى من نسيج دماغ الأغنام & جدول (4): التأثير التثبيطي لبعض المركبات = \\
\hline التأثير التبيطي \% & المركبات (1 ملي مولار) \\
\hline 0.00 & 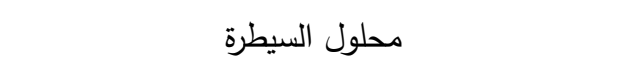 \\
\hline 56.1 & كلوريد الأمونيوم \\
\hline 49.9 & فلوريد الصوديوم \\
\hline 49.9 & فينايل هيدرازين \\
\hline 37.5 & آزيد الصوديوم \\
\hline 25 & أثيلين ثنائي الأمين رباعي حامض الخليك EDTA \\
\hline
\end{tabular}

\section{References}

1) Pal M. Janda T. Journal Plant Sce Phytopathol, 1: 95-100.(2017).

2) Poodeh S.H. Ph. D . Thesis, Science college university of Oulu P. 30. (2016).

3) Eom S.H., Lee J.K., Kim H., Jang K., Ryu H. and Hyun T.K. Acta Bot. Croat, 77(1): 97-101 (2018).

4) Del Duca S., Serafini-Fracassini D. and Cai G. Plant Polyamines in Stress and Development, 98 (2014).

5) Angelini R., Cona A., Federico R., Fincato P., Tavladoraki P. and Tisi A. An update. Plant Physiology and Biochemistry 48: $560-564$ (2010).

6) Blaschko H. Pharmacol. Rev. 4, 415-458 (1952).

7) Elovaara H., Huusko T.,Maksimow M.,Elima K., Yegutkin G.G., Skurnik M., Dobrindt U., Siitonen A., Mcpherson M.J., Salmi M. and Jalkanen S.PLoS ONE, 10(11): 142367 (2015).

8) Mcewen Ch.M. Journal Biol Chem. Vol. 240-2011 (1965).

9) Elliott J., Callingham B.A. and Sharman D.F. Comp. Pharmacol. Toxicol., 102(1): 83-89 (1992).

10) Subramanyam S., Sardesai N., Minoch S.C., Zheng C., Shukle R.H. and Williams C.E. BMC Plant Biology, 15-3 (2015).

11) Dahel K., Flayeh K.A. and Al-Saffar N.M. Neueochem. Res., 26(4): 415-418 (2001).

12) Al-Kateb S.M.Y., Ph.D. Thesis, College of Education For Pure Science, University of Mosul (2000).(In Arabic).

13) Al-Abbasy O.Y.M., M.Sc. Thesis, College of Education For Pure Science, University of Mosul (2003). ( In Arabic).

14) Schacterle G.R. and Pollack J.K. Anal. Biochem., 51: 654-655 (1973).

15) Lowrey O.H., Rosebrough N.J., Farr A.L. and Randall R.J. J.Biol.Chem., 193: 265-275 (1951).

16) Flayeh K.A. Clin. Chem., 34: 2401-2403 (1988).

17) Tabor C.W. and Kellogg P.D. J.Biol.Chem., 245(20): 5424-5433 (1970). 
18) Hames B.D. and Hooper N.M. "Instant notes on biochemistry", $2^{\text {nd }}$ Ed. Bio.Scientific publishers Limited (2000).

19) Al-Lehebe N.I.A., Ph.D. Thesis, College of Education, University oh Tikrit (2013). (In Arabic).

20) Suzuki O., Matsumoto T. and Katsumata K. Experientia, 40: 838-839 (1983).

21) Touhala W.I.A., Ph.D. Thesis, College of Education For Pure Science, University of Mosul (2006). (In Arabic).

22) Cervelli M., Cona A., Angelini R., Pdticelli F., Federico R. and Mariottini P. Eur. J. Biochem., 268 (13): 3816-3830. (2001).

23) Al-Abbasy O.Y.M., J. Tikrit for pure Scie., 15:3 (2008).

24) Ahmad T.Y.,"Biochemistry, Part One". 1nd Ed. Al_Hilali L.A.A. Company. Dar Ibn Al_Atheer, University of Mosul Page 278 and 187. (2010). .

25) Al-Rubaie M.J.M., M.Sc. Thesis, College of Education For Pure Science, University of Mosul (2013). (In Arabic).

26) Gahl W.A., Vale A.M. and Pitot H.C. Biochem. J., 202-603 (1980).

27) Seiler N., Bolkenius F.N., Knodgen B. and Mamond P. Biochem. Biophys. Actav., 615-418 (1980).

28) Rodwell V.W., "Harpers Biochemistry". 22th Ed. A Lange Medical Book Appleton and Lange, Chapter 10, P. 82.(1990).

29) Holtta E. J. Exp. Med. 97: 327-344 (1977).

30) Stephen H.F., Keith L.M., George I.H.H. and Frank R.N.G. Biochemistry 19, 3039-3047 (1980).

31) Zeller E.A., "In the enzymes: Chemistry and mechanism of action" $2^{\text {nd }}$ Ed. Sumner J.B. and Myrback K., New York, Academic press, Inc.(1950).

32) Yangisawa H., Kato A., Hoshiai S., Kamiya A. and Torri N. Plant Physiol., 85: 906-909 (1987).

33) Hirsch J.G. J. Exp. Med., 97: 327-344 (1953). 